[Agr. Biol. Chem., Vol. 32, No. 4, p. 417 423, 1968]

\title{
Determination of Fructose in the Presence of a Large Excess of Glucose
}

\author{
Part II. A Modified Anthrone-Sulfuric Acid Method and a Modified \\ Phenol-Sulfuric Acid Method
}

\author{
By Michinori Nakamura \\ Department of Agricultural Chemistry, The University of Tokyo, Bunkyo-ku, Tokyo
}

Received September 25, 1967

\begin{abstract}
Modifications of the anthrone-sulfuric acid method and the phenol-sulfuric acid method are described. By employing the principle of two-point determination of Mokrasch and by modifying the conditions for color development, fructose in the presence of 100 -fold excess of glucose can be determined with an error of about $15 \%$ by the modified anthronesulfuric acid method. The modified phenol-sulfuric acid method also gave the same order of sensitivity and specificity to fructose as the modified anthrone-sulfuric acid method.
\end{abstract}

The anthrone-sulfuric acid method has been used as a general color reaction of carbohydrates and on this basis has been employed as the method of choice for the determination of total sugars. However, as far as the author is aware, Koehler ${ }^{1 /}$ was the first who developed a method using anthrone- $\mathrm{H}_{2} \mathrm{SO}_{4}$ reagent for distinguishing fructose from glucose on the basis of different rates of color development and different color intensities of these two sugars. Since then, several workers ${ }^{2-5}$ developed methods for the determination of fructose in the presence of glucose by controlling the conditions of color development so that fructose developed color while glucose remained inactive or reacted only to a small extent. Bonting ${ }^{6 /}$ proposed an ultra-micro method by which color was developed in a

1) L. H. Koehler, Anal. Chem., 24, 1576 (1952).

2) J.R. Helbert and K. D. Brown, ibid, 27, 1791 (19.55).

3) M. Wenke and J. Labská, Casopis lékáru ceskych,

93, 23 (1954) [C. A., 48, 12862e (1954)].

4) C.S. Wise, R.J. Dimler, H. A. Davis and C. E.

Rist, Anal. Chem., 27, 33 (1955).

5) M. A. Jermyn, Nature, 177, 38 (1956).

6) S. L. Bonting, Arch. Biochem. Biophys., 52, 272 (1954). total volume of $75 \mu \mathrm{l}$. This method permits the measurement of the smallest amount of fructose among various methods ever proposed, but requires a special micro technique and special apparatuses (a sensitive spectrophotometer and a micro-cell attachment), and is not applicable in ordinary laboratories. Moreover, since this method is based on color development by the heat evolved spontaneously during mixing of the reagents, the conditions (size and wall thickness of test tubes, the rate of mixing the components, etc.) should be followed rigorously in order to obtain reproducible results, and the total volume is not to be scaled up without re-examinations of the reaction conditions. Mokrasch ${ }^{7}$ observed that fructose and glucose gave very different patterns of color development in the anthrone$\mathrm{H}_{2} \mathrm{SO}_{4}$ method; i.e., fructose gave maximum color (at $620 \mathrm{~m} \mu$ ) in $3 \mathrm{~min}$ at $80 \mathrm{C}$ and then the color was decreased, whereas glucose gave the highest color at about $25 \mathrm{~min}$ at the same temperature. Therefore, by measuring the color of fructose, glucose and the mixture of

7) L. C. Mokrasch, J. Biol. Chem., 208, 55 (1954). 
the two sugars at 3 and $25 \mathrm{~min}$, the contents of fructose and gluctose in the mixture can be obtained by calculation. Moreover, this method seemed to be one of the most sensitive methods based on anthrone thus far proposed in the literature. Thus, this method was employed as the basis of a further study. By employing Mokrasch's principle of twopoint determination and lowering the reaction temperature to $50^{\circ} \mathrm{C}$, fructose in the presence of 100 -fold excess of glucose can be determined with an error of about $15 \%$.

The phenol-sulfuric acid method of DuBois et al. ${ }^{81}$ has also been widely used as a method for the determination of total sugars. However, this method has never before been used in the preferential determination of fructose in the presence of glucose. In view of the success obtained with the modified anthronesulfuric acid method, conditions of this method were re-examined in order to find out a suitable procedure for our purposes (see the preceding paper $\left.{ }^{9 \prime}\right)$. Because the results obtained were comparable to but not more promising than the modified anthrone method, this method was not investigated further. However, some data obtained during this investigation are presented here so that some investigators interested in this reaction can utilize these data as a basis for their further studies. One advantage of this method is that the reagent, phenol, is much less expensive than anthrone.

It is reported that fructose also reacts with a mixture of phenol, acetic acid and sulfuric acid to give a green color. Based on this color reaction, Maurmeyer et al. ${ }^{1 \sim 12)}$ developed a

8) M. DuBois, R. Gilles, J. K. Hamilton, P. A. Rebers and F. Smith, Anal. Chem., 28, 350 (1956).

9) M. Nakamura, Agr. Biol. Chem, 32, 412 (1968).

10) R. K. Maurmeyer, E. M. Livingston and H. Zahnd, J. Biol. Chem., 185, 347 (1950).

II) R. K. Maurmeyer, E. M. Livingston, R. Michaels, Mikrochim. Acta, 1956, 1600 [C. A., 51, $2475 h(1957)]$.

12) E. M. Livingston, R. K. Maurmeyer and A. Worthman, Microchem. J., 1, 261 (1957) [C. A., 52, 2664d (1958)]. qualitative test as well as a quantitative method for fructose.

After this work was completed, Handel ${ }^{131}$ used anthrone- $\mathrm{H}_{2} \mathrm{SO}_{4}$ reagent at room temperature to determine successfully fructose in the presence of 10 -fold excess of glucose by this procedure.

\section{EXPERIMENTAL}

Reagents. Anthrone reagent is prepared by dissolving $100 \mathrm{mg}$ of anthrone (Tokyo Kasei Co.) in cold diluted $\mathrm{H}_{2} \mathrm{SO}_{4}$ which has been prepared by adding $100 \mathrm{ml}$ of conc. $\mathrm{H}_{2} \mathrm{SO}_{4}$ to $29 \mathrm{ml}$ of distilled water under cooling in running tap water. This reagent is usable for more than one month when stored in a dark bottle in a refrigerator. Phenol reagent is prepared by mixing $80 \mathrm{~g}$ of redistilled phenol with $20 \mathrm{~g}$ of distilled water. This reagent is stable for a long time in a refrigerator, and on color change to pink, is discarded and prepared fresh.

Other details are described in the preceding paper.")

\section{RESULTS AND DISCUSSION}

\section{A. Anthrone-sulfuric acid method.}

Principle of the method. Small test tubes (14 $\mathrm{mm}$ i.d. $\times 100 \mathrm{~mm}$ ) containing $3.6 \mathrm{ml}$ of the anthrone reagent are cooled in ice water and to each tube is added, slowly and without mixing, $0.6 \mathrm{ml}$ of a sugar solution. After the tubes are incubated for a further few minutes in ice water, the tubes are shaken and then transferred to a water bath kept at a constant temperature. After the incubation for various time intervals, the tubes are cooled in running tap water and the absorbances at $625 \mathrm{~m} \mu$ are read in a spectrophotometer.

Figure 1 shows the time course of color development when $30 \mu \mathrm{g}$ each of fructose and/or glucose are used as the sugar and the incubations are at $80 \pm 1^{\circ} \mathrm{C}$ (as specified by Mokrasch ${ }^{71}$ ). It is evident from the figure that fructose gives maximum color at $2 \sim 5$ min and then the color decreases slowly with time. On the other hand, glucose color is maximum at $20 \sim 30 \mathrm{~min}$. A mixture of fructose and glucose gives a progress curve which

13) E. V. Handel, Anal. Biochem., 19, 193 (1967). 


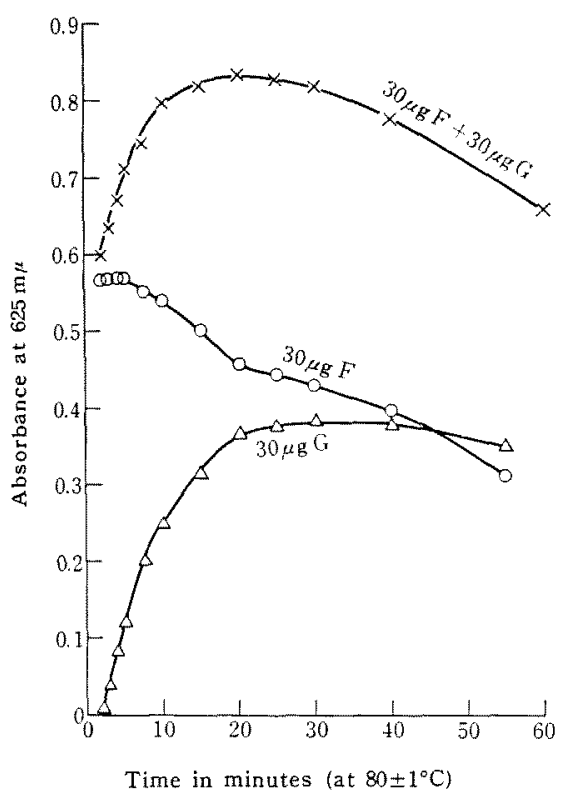

FIG. 1. Time Course of Color Development in the Modified Anthrone-Sulfuric Acid Method.

The reaction mixture contained $3.6 \mathrm{ml}$ of the anthrone-sulfuric acid reagent and $0.6 \mathrm{ml}$ of a sugar solution containing fructose (F) and/or glucose $(G)$ as indicated in the figure. The components were mixed in ice-water and then heated in a water bath at $80 \pm 1^{\circ} \mathrm{C}$ for various times.

is almost identical to the sum of fructose and glucose curves.

In the method of Mokrasch, $t_{1}$ and $t_{2}$ were 3 and $25 \mathrm{~min}$, respectively. Because $D_{t_{1}}$ and $D_{t_{2}}$ may equal to the sum of colors of fructose and glucose at respective heating times, then we obtain

and

$$
D_{t_{1}}=C_{F} \cdot E_{F}+C_{G} \cdot E_{G} \cdot k_{G}
$$

$$
D_{t_{2}}=C_{F} \cdot E_{F} \cdot k_{F}+C_{G} \cdot E_{G}
$$

Solving these equations, we obtain

and

$$
C_{F}=\left(D_{t_{1}}-k_{G} \cdot D_{t_{2}}\right) / E_{F}\left(1-k_{F} \cdot k_{G}\right)
$$

$$
C_{G}=\left(D_{t_{2}}-k_{F} \cdot D_{t_{1}}\right) / E_{G}\left(1-k_{F} \cdot k_{G}\right)
$$

where

$E_{F}$ : Absorbance at $625 \mathrm{~m} \mu$ obtained from $1 \mu$ mole of fructose at time $t_{1}$
$E_{G}$ : Absorbance at $625 \mathrm{~m} \mu$ obtained from $1 \mu$ mole of glucose at time $t_{2}$

$k_{F}$ : Ratio of absorbances at times $t_{2}$ and $t_{1}$ for fructose

$k_{g}$ : Ratio of absorbances at times $t_{1}$ and $t_{2}$ for glucose

$D_{t_{1}}$ and $D_{t_{2}}$ : Absorbances of the sample at times $t_{1}$ and $t_{2}$, respectively

$C_{F}: \mu$ moles of fructose in the $0.6 \mathrm{ml}$ of the sample

$C_{G}:$ moles of glucose in the $0.6 \mathrm{ml}$ of the sample

Time course of color development at various temperatures. A survey of the literature shows that there is some variations in the concentrations of reagents among many methods based on the anthrone- $\mathrm{H}_{2} \mathrm{SO}_{4}$ color reaction; especially, the temperature and time of heating. For example, the conditions used and millimolar absorbance values $\left(\varepsilon \times 10^{-3}\right)^{*}$ (given in parenthesis) obtained by various investigators are: Koehler, ${ }^{\prime \prime} 1 \sim 2 \mathrm{~min}$ at $98^{\circ} \mathrm{C}$ (1.83); Helbert and Brown, ${ }^{2} 7 \mathrm{~min}$ at $60^{\circ} \mathrm{C}$ (13.0); Wenke and Labská," $8 \mathrm{~min}$ at $50 \sim 51$ ${ }^{\circ} \mathrm{C}$; Wise et al. ${ }^{4)} 20 \pm 0.1 \mathrm{~min}$ at $50 \pm 0.5^{\circ} \mathrm{C}$ (15.7); Jermyn, ${ }^{5} 20 \sim 60 \mathrm{~min}$ at room temperature $\left(17^{\circ} \mathrm{C}\right)(0.94$ at $10 \mathrm{~min}$ and 2.26 at $60 \mathrm{~min})$; Bonting, ${ }^{61} \quad 10 \sim 50 \mathrm{~min}$ at room temperature (8.37); and Mokrasch, ${ }^{71} 3 \mathrm{~min}$ at $80^{\circ} \mathrm{C}$ (21.7). Thus, these workers searched for the condition under which fructose color is nearer to the maximum and, at the same time, glucose color is nearer to the minimum. The twopoint determination of Mokrasch presumes that these two requirements will never be satisfied simultaneously. Therefore, in principle, the condition of color development is not important, provided there is no error in the determinations. But, in practice, small errors in the determinations are inevitable, and they influence seriously on subsequent calculations. Therefore, in order to find out

* The millimolar absorbance values given here were calculated by the author from the data given in the literature. 


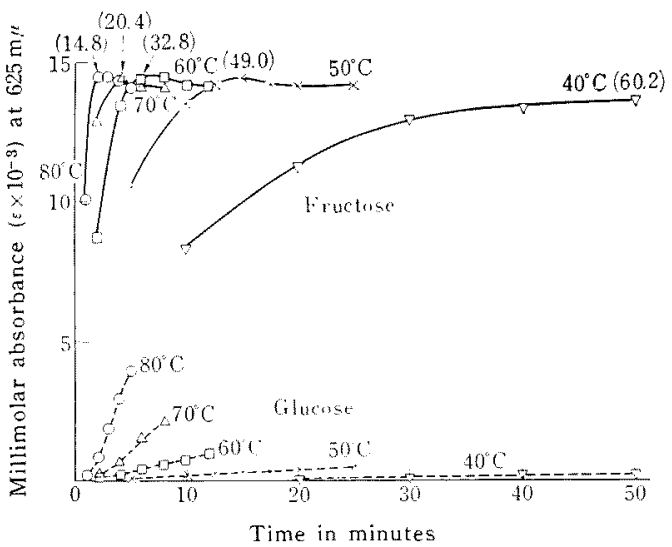

FIG. 2. Time Course of Color Development in the Modified Anthrone-Sulfuric Acid Reaction at Various Temperatures.

Experimental details are the same as given in the legend to Fig. I, except the reaction mixture was heated in a water bath maintained at various temperatures as indicated in the figure. The figures in parentheses on each fructose curve shows the color intensity ratio of fructose to glucose at the time of maximum fructose color at each temperature.

a condition under which errors in the determinations will have minimum influence on subsequent calculations, it seems necessary to compare the time course of color development by both fructose and glucose at various temperatures.

Figure 2 shows the time course of color development by fructose and glucose at various temperatures between 40 and $80^{\circ} \mathrm{C}$. When the temperature is varied, the time course differs to a remarkable extent, especially with glucose. The time course of the color intensity ratio of fructose to glucose, as calculated from the data of Fig. 2, is shown in Fig. 3. Since there is a remarkable difference between the rates of color development of both sugars at various temperatures, the color intensity ratio at the time of the maximum fructose color varies with the temperature; the larger is the ratio, the lower the temperature. Because the maximum color of fructose is practically constant between $50 \sim 80^{\circ} \mathrm{C}$, a lower temperature is to be preferred in order to more satisfy

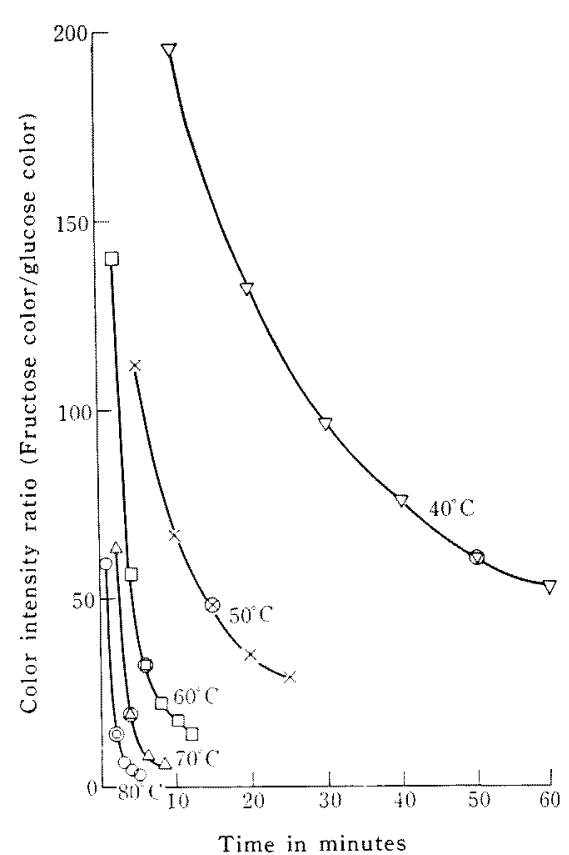

FIG. 3. Time Course of the Color Intensity Ratio of Fructose to Glucose at Various Temperatures.

Calculated from the data of Fig. 2. The point on each curve surrounded by a circle indicates the time when the fructose color is at the maximum.

the two requirements of sensitivity and specificity. At $40^{\circ} \mathrm{C}$, the rate of color development is too slow.

When the method of Mokrasch is examined with the above results in mind, apparently glucose may develop an appreciable color even after heating for $3 \mathrm{~min}$ at $80^{\circ} \mathrm{C}$. Therefore, when a sample solution contains a large excess of glucose over fructose, glucose color will represent a greater portion of the sample color even at $3 \mathrm{~min}$. Mokrasch selected the $3 \mathrm{~min}$ and $25 \mathrm{~min}$ heating times at $80^{\circ} \mathrm{C}$ because his aim was to determine both fructose and glucose simultaneously. In order to determine fructose content preferentially and as accurately as possible, it would be better to develop color at $50^{\circ} \mathrm{C}$ and select two times: one at the maximum fructose color, and the other an appropriate time for the convenience 
Table I. Determination of Fructose in the Presence of 100-Fold Excess of Glucose by the Modified Anthrone-Sulfuric ACid Method

\begin{tabular}{ccccccrr}
$\begin{array}{c}\text { Experiment } \\
\text { No. }\end{array}$ & $E_{F}$ & $E_{G}$ & $k_{F}$ & $k_{G}$ & \multicolumn{2}{c}{ Calculated } & $F_{*}^{* * *}$ \\
1 & 3.42 & 0.150 & 0.977 & 0.387 & 8.30 & 920 & 25.3 \\
2 & 3.31 & 0.148 & 0.940 & 0.388 & 8.70 & 1010 & 26.2 \\
3 & 3.34 & 0.151 & 1.03 & 0.381 & 9.80 & 966 & 26.4 \\
4 & 3.50 & 0.153 & 1.07 & 0.393 & 8.85 & 1027 & 25.6 \\
5 & 3.44 & 0.153 & 1.04 & 0.379 & 9.43 & 976 & 26.0 \\
6 & 3.71 & 0.157 & 0.965 & 0.392 & 8.55 & 990 & 24.9 \\
7 & 3.52 & 0.149 & 0.995 & 0.400 & 10.1 & 947 & 26.2 \\
8 & 3.68 & 0.162 & 1.03 & 0.410 & 10.0 & 945 & 26.9 \\
$9 *$ & 3.51 & 0.255 & 1.05 & 0.284 & 11.7 & 865 & 29.6 \\
$10^{* *}$ & 3.74 & 0.186 & 1.02 & 0.356 & 9.97 & 913 & 26.0
\end{tabular}

The reaction mixture contained $3.6 \mathrm{ml}$ of the anthrone reagent and $0.6 \mathrm{ml}$ of sugar solution containing either $10 \mu \mathrm{g}$ of fructose or $1.0 \mathrm{mg}$ of glucose, or a mixture of $10 \mu \mathrm{g}$ of fructose and $1.0 \mathrm{mg}$ of glucose. The components were mixed in ice water and heated in a water bath at $50 \pm 0.1^{\circ} \mathrm{C}$ for 15 and $40 \mathrm{~min}$. Absorbance was read against a reagent blank prepared with distilled water in place of a sugar solution. See the text for symbols.

* Heating times $\left(t_{1}\right.$ and $t_{2}$ ) were 15 and $60 \mathrm{~min}$, respectively.

** Heating times $\left(t_{1}\right.$ and $t_{2}$ ) were 14 and $40 \mathrm{~min}$, respectively.

*** Calculated by the usual one-point determination principle (absorbance was measured after heating for $15 \mathrm{~min}$ ).

of the experiment and not necessarily the time at the maximum glucose color.

From the results of Figs. 2 and 3 and other similar experiments, it seemed appropriate to select 15 and $40 \mathrm{~min}$ heating times at $50^{\circ} \mathrm{C}$. Table I shows the results of 10 such experiments in which a mixture of $10 \mu \mathrm{g}$ of fructose and $1.0 \mathrm{mg}$ of glucose per $0.6 \mathrm{ml}$ of the sample solution was assayed by the above procedure. Although the time course of color development as well as the absolute color intensity of fructose or glucose varies more or less from experiment to experiment, fructose in the presence of 100 -fold excess of glucose may be determined with an error of about $15 \%$. The last column of Table I shows the results obtained when the fructose content was determined by the principle of one-point determination; i.e., the fructose content was obtained from the absorption value of the sample tube at $15 \mathrm{~min}$ heating by consulting with a calibration curve of fructose. The advantage of the two-point determination is obvious when the results obtained by the two methods are compared with each other.

Recommended procedure. Eight small test tubes containing $3.6 \mathrm{ml}$ of the anthrone reagent are incubated in ice-water and to two tubes each are added $0.6 \mathrm{ml}$ of distilled water, a standard fructose solution, a standard glucose solution, and the sample solution, respectively. The tubes are incubated in ice-water for a further few min, shaken to mix the components, and then transferred to a water bath at $50 \pm 0.1 \mathrm{C}$. After 15 and $40 \mathrm{~min}$ heating, 4 tubes each from the different series are removed and transferred back to the ice-water bath. Absorbances of the sugar tubes at 625 $\mathrm{m} \mu$ are read against the reagent blank tube prepared with distilled water. Fructose and glucose contents are calculated from equations (1) and (2) given in the text, in which $t_{1}$ and $t_{2}$ represent 15 and $40 \mathrm{~min}$, respectively.

B. Phenol-sulfuric acid method.

Time course of color development with fructose and glucose at various temperatures. Small test tubes containing $3.0 \mathrm{ml}$ of conc. $\mathrm{H}_{2} \mathrm{SO}_{4}$ are incubated in an ice-water bath for at least 
5 min. To each tube are added, slowly and without mixing, $1.2 \mathrm{ml}$ of a sugar solution and $0.03 \mathrm{ml}$ of $80 \%$ phenol reagent. The tubes are incubated in ice-water for a further few min, shaken well to mix the components, and then left at room temperature $\left(27 \sim 28^{\circ} \mathrm{C}\right)$. During mixing of the components, there was some evolution of heat, although the components had been sufficiently cooled in icewater. There was also a slightly yellow color appearing in the mixed solution, but this color faded after a few min. The absorption spectra for fructose and glucose both gave absorption maxima at $490 \sim 494 \mathrm{~m} \mu$. Figure 4 shows the time course of color development as observed at $490 \mathrm{~m} \mu$. The color development with fructose was rather rapid during the first hour, then slowed down and remained practically constant after the second hour, while the glucose color increased continuously for at least $4 \mathrm{hr}$. The time course of color develop-

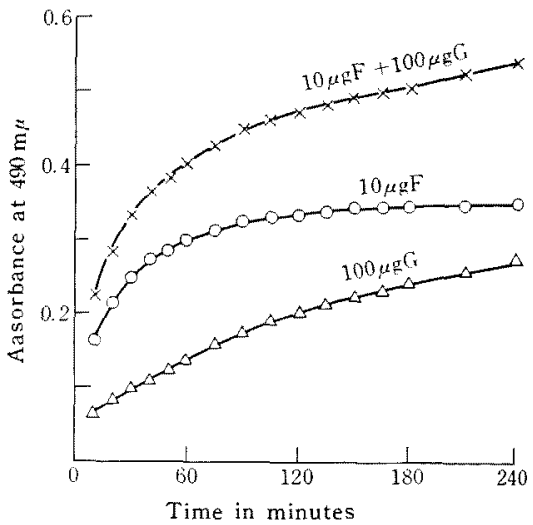

FIG. 4. Time Course of Color Development in the Phenol-Sulfuric Acid Reaction.

The reaction mixture contained $3.0 \mathrm{ml}$ of conc $\mathrm{H}_{2} \mathrm{SO}_{4}, 1.2 \mathrm{ml}$ of a sugar solution containing fructose $(F)$ and/or glucose $(G)$ as indicated in the figure, and $0.03 \mathrm{ml}$ of $80 \%$ aq. phenol. The components were mixed in ice-water, and then left at room temperature $\left(27 \sim 28^{\circ} \mathrm{C}\right)$ for various times as indicated in the figure.

Table II. Time Course of Color Development in the Phenol-Sulfuric acid REACTION AT VARIOUS TEMPERATURES

\begin{tabular}{|c|c|c|c|c|c|c|c|c|c|c|c|c|c|c|c|}
\hline & \multicolumn{14}{|c|}{ Time in minutes } \\
\hline & & 2 & 4 & 6 & 8 & 10 & 15 & 20 & 25 & 30 & 40 & 60 & 120 & 180 & 240 \\
\hline \multirow{6}{*}{$\mathrm{F}$} & $80^{\circ}$ & 20.8 & 23.6 & 22.6 & & & & & & & & & & & \\
\hline & $70^{\circ}$ & 20.7 & 23.3 & 24.4 & 24.4 & 23.4 & 22.2 & & & & & & & & \\
\hline & $60^{\circ}$ & & 21.0 & & 22.4 & & 23.6 & 23.1 & & 22.7 & & & & & \\
\hline & $50^{\circ}$ & & & & & 22.2 & & 23.0 & 24.3 & 24.2 & 24.1 & 24.1 & & & \\
\hline & $40^{\circ}$ & & & & & 19.1 & & 21.1 & & 24.1 & 24.2 & 24.3 & 26.2 & & \\
\hline & Room & temp. & $(27 \sim$ & $\left.28^{\circ} \mathrm{C}\right)$ & & 12.6 & & 16.6 & & 19.1 & 20.7 & 22.9 & 25.5 & 26.1 & 26.7 \\
\hline \multirow{6}{*}{ G. } & $80^{\circ}$ & 4.05 & 10.9 & 11.9 & & & & & & & & & & & \\
\hline & $70^{\circ}$ & $3.2+$ & 8.50 & 10.3 & 10.4 & 10.8 & 11.3 & & & & & & & & \\
\hline & $60^{\circ}$ & & 3.46 & & 6.74 & & 8.84 & 9.11 & & 9.53 & & & & & \\
\hline & $50^{\circ}$ & & & & & 1.78 & & 3.19 & 3.43 & 4.61 & +.99 & 5.92 & & & \\
\hline & $40^{\circ}$ & & & & & 1.30 & & 1.03 & & 1.48 & 2.36 & 1.89 & 2.81 & & \\
\hline & Room & temp. & 272 & $\left.28^{\circ} \mathrm{C}\right)$ & & 0.503 & & 0.647 & & 0.785 & 0.861 & 1.07 & 1.53 & 1.83 & 2.08 \\
\hline \multirow{6}{*}{$\begin{array}{l}\text { Ratio, } \\
\text { F./G. }\end{array}$} & $80^{\circ}$ & $5.1+$ & 2.16 & 1.90 & & & & & & & & & & & \\
\hline & $70^{\circ}$ & 6.39 & 2.74 & 2.37 & 2.34 & 2.17 & 1.97 & & & & & & & & \\
\hline & $60^{\circ}$ & & 6.07 & & 3.33 & & 2.67 & 2.54 & & 2.39 & & & & & \\
\hline & $50^{\circ}$ & & & & & 12.5 & & 7.22 & 7.00 & 5.25 & 4.83 & 4.07 & & & \\
\hline & $40^{\circ}$ & & & & & 14.7 & & 20.5 & & 16.3 & 10.2 & 12.8 & 9.34 & & \\
\hline & Room & temp. & $(27 \sim$ & $\left.28^{\circ} \mathrm{G}\right)$ & & 25.0 & & 25.7 & & 24.4 & 24.0 & 21.4 & 16.7 & 14.3 & 12.8 \\
\hline
\end{tabular}

The reaction mixture contained $3.0 \mathrm{ml}$ of conc. $\mathrm{H}_{2} \mathrm{SO}_{4}, 1.2 \mathrm{ml}$ of a sugar solution containing an appropriate amount of either fructose or glucose (depending on the temperature used), and $0.03 \mathrm{ml}$ of $80^{\circ}$ aq. phenol. The components were mixed in ice-water and transferred to a water bath maintained at the specified temperature for various times. The absorbance was expressed in terms of millimolar absorbance $\left(\varepsilon \times 10^{-3}\right)$ units. 
Table III. Color Development in a Modified Phenol-Sulfuric Acid Reaction

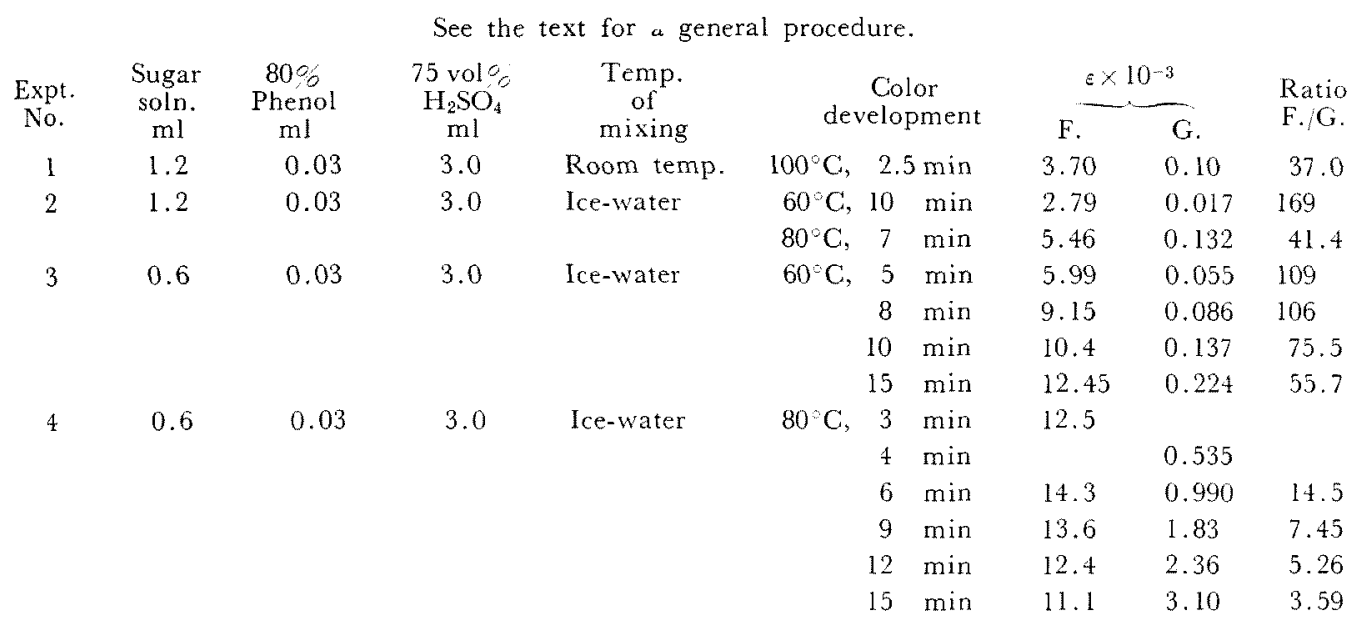

ment with fructose and glucose and the color intensity ratio of these two sugars at various temperatures are shown in Table II. As is evident from the table, the sensitivity of this modified procedure for fructose is about twice as high as the original method $\left(\varepsilon<10^{-3}=11.3\right)$. However, this method also gives a higher color intensity to glucose, thus leading to a lower color intensity ratio (i.e., a lower specificity for fructose) when compared to similar results obtained by the modified anthrone$\mathrm{H}_{2} \mathrm{SO}_{4}$ method.

A modified procedure using $75 \%$ sulfuric acid. In order to eliminate the heat evolved spontaneously during dilution of the conc. $\mathrm{H}_{2} \mathrm{SO}_{4}$ reagent referred to in the preceding section, the concentration of the sulfuric acid reagent was reduced to $75 \%$, because it was probable that the heat was responsible to the high glucose color obtained. Table III shows the results of some experiments in which fructose and glucose were treated under various conditions. When the volume ratio of $75 \% \mathrm{H}_{2} \mathrm{SO}_{4}$ and the sugar solution was kept the same as in the original method, the color intensity obtained with fructose was very low, owing to the reduced concentration of sulfuric acid in the final reaction mixture. When the volume of the sugar solution was reduced to $1 / 2$ in order to keep the final sulfuric acid concentration as high as possible, the sensitivity and specificity to fructose obtained was comparable to those in the modified anthronesulfuric acid method. But, because this method did not seem to be more promising than the modified anthrone-sulfuric acid method, it was not investigated further. 